\title{
Identifying climatic drivers of tropical forest dynamics
}

\author{
M. Aubry-Kientz ${ }^{1}$, V. Rossi ${ }^{2,3,4}$, F. Wagner ${ }^{2,5}$, and B. Hérault ${ }^{2}$ \\ ${ }^{1}$ Université des Antilles et de la Guyane, UMR Ecologie des Forêts de Guyane, Campus agronomique \\ de Kourou, Kourou, France \\ ${ }^{2}$ CIRAD, UMR Ecologie des Forêts de Guyane, Campus agronomique de Kourou, Kourou, France \\ ${ }^{3}$ CIRAD, UPR Bsef, Montpellier, France \\ ${ }^{4}$ Université de Yaoundé I, UMMISCO (UMI209), BP337, Yaoundé, Cameroon \\ ${ }^{5}$ Remote sensing division, National Institute for Space Research-INPE, São José dos Campos, SP, Brazil
}

Correspondence to: B. Hérault (bruno.herault@cirad.fr)

Received: 25 November 2014 - Published in Biogeosciences Discuss.: 11 February 2015

Revised: 18 May 2015 - Accepted: 9 September 2015 - Published: 1 October 2015

\begin{abstract}
In the context of climate change, identifying and then predicting the impacts of climatic drivers on tropical forest dynamics is becoming a matter of urgency. To look at these climate impacts, we used a coupled model of tropical tree growth and mortality, calibrated with forest dynamic data from the 20-year study site of Paracou, French Guiana, in order to introduce and test a set of climatic variables. Three major climatic drivers were identified through the variable selection procedure: drought, water saturation and temperature. Drought decreased annual growth and mortality rates, high precipitation increased mortality rates and high temperature decreased growth. Interactions between key functional traits, stature and climatic variables were investigated, showing best resistance to drought for trees with high wood density and for trees with small current diameters. Our results highlighted strong long-term impacts of climate variables on tropical forest dynamics, suggesting potential deep impacts of climate changes during the next century.
\end{abstract}

\section{Introduction}

Tropical forests are characterized by high annual precipitation and high evapotranspiration. Nevertheless, strong seasonal variations in rainfall inputs, partly driven by atmospheric movements related to the monsoon or latitudinal changes in the inter-tropical conversion zone, occur in most tropical regions around the world (Feng et al., 2013). Such seasonality implies various changes of the availability of resources, such as water and light, necessary to tree devel- opment and to forest functioning. The seasonality of tree growth and tree mortality is increasingly studied in tropical forests, with some studies having succeeded in linking seasonal tree demography to climate seasonality (Wagner et al., 2012; Grogan and Schulze, 2012; Brando et al., 2010). Tree growth is mainly related to water availability, resulting in growth during the wet months and static or even contracted states during the dry season months (Grogan and Schulze, 2012). The use of a convenient water availability proxy like the relative extractable water (REW; Wagner et al., 2011) shows that low levels of REW rather than lack of rainfall per se are the key drivers of the decrease in growth rate, or even of the stop, at a seasonal time step (Wagner et al., 2012).

At another timescale, long-term forest dynamic changes may also be related to exceptional climate events. Effects of unusual dry periods on tree growth and mortality may enlighten us about the long-term processes linking water availability and tree dynamics. After the intense 2005 drought in Amazonia, the forest suffered an additional mortality, leading to a huge loss of alive tree biomass (Phillips et al., 2009). Similar major mortality events were observed in Panama (Condit, 1995), in Chinese rain forests (Tan et al., 2013) or in South-East Asia (Slik, 2004). Water exclusion experiments in Brazil provide results in line with a deep impact of drought on tree mortality (Nepstad et al., 2007; da Costa et al., 2010; Brando et al., 2008).

Between the timescale of exceptional events and the timescale of intra-annual seasonal rhythmicity, there is a gap in our knowledge on the inter-annual scale. This gap is partly due to the weak magnitude of variation of the demographic 
rates when compared to what is observed from a seasonal point of view or to some spectacular events. This gap is also due to the lack of sites in tropical forests where annual regular inventories of tree growth and death are performed and where precise climatic data on the same timescale are available. Moreover, the potential links between inter-annual climate variations and tropical forest dynamics should be studied from a multi-decadal long-term perspective in order to be representative of the climatic variability and of the variability of forest dynamic responses (Clark et al., 2010).

Some climatic variables (mainly water stress, water saturation and temperature) are expected to play a role in forest dynamics regarding the tree's physiological processes. Water stress due to drought is well documented (Phillips et al., 2009; Allen et al., 2010). Water insufficiency leads generally to higher mortality rates and lower growth (Choat et al., 2012). Water stress needs to be estimated, and diverse estimators may be found in the literature (Wagner et al., 2011; Toledo et al., 2011; Aragão et al., 2007; Malhi et al., 2009). The length of the dry season seems to be the simplest estimator. The relative extractable water (REW) described in the study of Wagner et al. (2011) estimates the quantity of water available for tree development and has been proved to have high performance in predicting intra-annual forest dynamics in Wagner et al. (2012). Although water availability is expected to reduce growth and increase mortality, these impacts have to be investigated on an inter-annual timescale. Rain may also be responsible for water saturation, a phenomenon that is far less studied but that can have an effect on tree mortality or growth. For instance, Ferry et al. (2010) underlined a higher mortality rate in waterlogged areas. Inter-annual variations of rain quantities can lead to more or less waterlogged soils, independent of their topographical location, implying instability that can cause cascading tree falls.

The effects of temperature are less consensual; some studies suggested that tropical forests can be near a high temperature threshold and that these systems may be more vulnerable to climate change than previously believed (Clark et al., 2003). For instance, Clark et al. (2003) showed a negative correlation between 16-year diameter increments and annual means of daily minimal temperature in La Selva, Costa Rica, while Toledo et al. (2011) found a positive correlation between annual diameter growth and temperature in Bolivia. An explanation for such apparently conflicting results was proposed by Dong et al. (2012): the effects of variability in solar radiation and daily minimum temperature on tree growth appear to be largely independent.

In this study, we use a modeling approach in order to mechanistically link climate conditions and functional plant traits to tree growth and survival (Zuidema et al., 2013). Functional traits have been recently used to include functional diversity in models of tree growth (Hérault et al., 2011; Rüger et al., 2012; Wagner et al., 2014) and tree mortality (Aubry-Kientz et al., 2013). We first question the potential relationships existing between climate variables computed on a 2-year time step and forest dynamics. We identify independent variable responsible for the inter-annual variation of growth and mortality rates. These variables are then included in a coupled growth-mortality model to test their multivariate effects. Finally, we include in the model some interactions between functional traits (wood density and tree size) and climate predictors to test for a potential differentiated response depending on the individual functional identity. First, tree species having high wood density have been reported to better resist drought events as compared to lower density ones (Phillips et al., 2010). Part of these differences is related to differences in hydraulic failure, as wood density is linked to xylem structure. Second, the current tree size also influences resistance to drought events or other climatic perturbations (Nepstad et al., 2007; Condit et al., 2004). Two main hypotheses are debated. First, small, young trees that are not well established and that do not have deep roots may be more sensitive and may suffer under stressful water conditions. Second, large, older trees may feel water stress because they must maintain their photosynthesis activities and carry water from tree roots to a higher altitude in the forest canopy.

\section{Materials and methods}

\subsection{Data collection}

Three data sets were used in this study. The study site is located in Paracou, French Guiana $\left(5^{\circ} 18^{\prime} \mathrm{N}, 52^{\circ} 55^{\prime} \mathrm{W}\right)$. The forest is typical of Guianan rain forests and the dominant tree families are Fabaceae, Chrysobalanaceae, Lecythidaceae, and Sapotaceae. More than 700 species of trees $\geq 10 \mathrm{~cm}$ DBH (diameter at breast height) have been described at the site.

Mean annual precipitation averages $2980 \mathrm{~mm}$ (30-year period), and the site receives nearly two-thirds of its annual precipitation during the long rainy season between mid-March and mid-June (Wagner et al., 2011), and less than $100 \mathrm{~mm}$ per month from August to November (Fig. 1).

\subsubsection{Tree dynamic}

The first data set is an inventory of trees $>10 \mathrm{~cm}$ DBH in the six natural forest plots of 6.25 ha in Paracou. Mortality and diameter growth have been calculated every 2 years between 1991 and 2011. DBH was calculated from circumference measures made to a precision of $0.5 \mathrm{~cm}$. We excluded individuals with buttresses or other problems that required an increase in measurement height because we were unsure about the height of the initial points of measurement for these trees. The data set contained 20340 trees from 642 species. For each tree and every 2 years, we know the location, DBH, vernacular name, status (dead or alive), and the mode of death for dead trees (tree fall or standing death). Vernacular names are the common names used by local tree spotters. As botanical identification of the trees species was completed in 


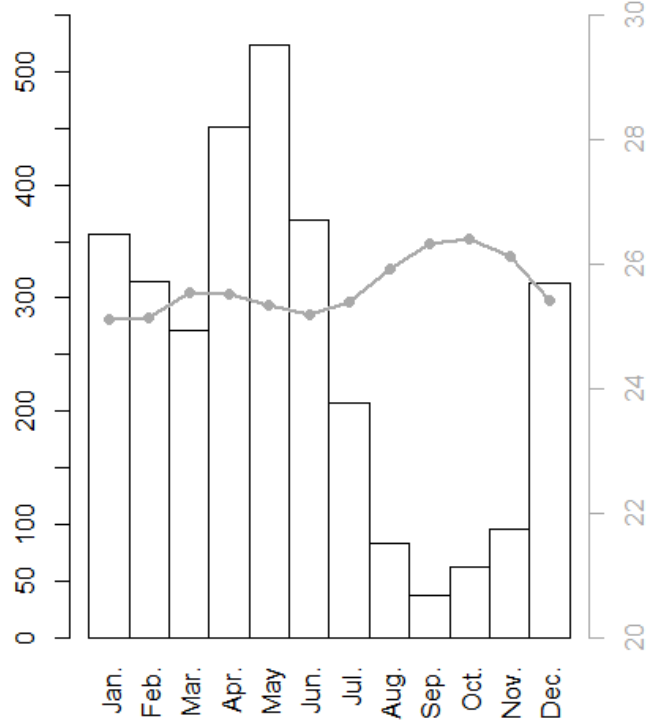

Figure 1. Ombrothermic diagram of the Paracou forest, data from the 2001-2014 time period (precipitation in meters) on the left, temperature in ${ }^{\circ} \mathrm{C}$ on the right.

2012, a large part of the trees that died during the study period (1991-2011) have only a vernacular name and no botanical determination. The method of Aubry-Kientz et al. (2013) is used to handle this uncertainty and to integrate the information on botanical determination contained in the vernacular names of trees that were not identified.

\subsubsection{Functional traits}

The second data set was a collection of five functional traits of 335 Guianan tree species that occur at the Paracou site (Table 1). These 335 species represent $79 \%$ of the total number of individual trees included in this study. We used the procedure described in Aubry-Kientz et al. (2013) to assign functional trait values to trees for which (i) the species is known but trait values were not available, (ii) the species was not determined at the species level and (iii) the tree was dead before being identified. Traits are related to leaf economics, stem economics and life history and are extracted from a large database (Baraloto et al., 2010a, b). The leaf economics reflects a trade-off between investments in productive leaves with rapid turnover versus costly physical leaf structure with a longer payback. The stem economics defines a similar trade-off at the stem level: dense wood versus high wood water content and thick bark (Baraloto et al., 2010b). Life-history strategies describe how trees allocate resources to different organs and how these allocations translate into a species' ability to compete for resources and finally to grow, survive, reproduce and disperse (Rüger et al., 2012). Some of these functional traits are accurate proxies of growth trajectories (Herault et al., 2010; Hérault et al., 2011) and mortality rates (Aubry-Kientz et al., 2013).

\subsubsection{Climate}

The third data set consists of climate data (Table 2). Six variables were provided by the Climatic Research Unit (CRU) at the University of East Anglia (Mitchell and Jones, 2005), consisting in month-by-month variations in climate over the last century calculated on high-resolution grids $\left(0.5 \times 0.5^{\circ}\right.$; Mitchell and Jones, 2005). We used the aggregated variables (mean or sum, depending of the nature of the observed process) for 2 years, from July to July, to include the dry season (mid-August to mid-November). Selected variables that may have an impact on forest dynamics are the cloud cover (Cld), the potential evapotranspiration (Pet), the precipitation (Pre), the daily mean temperature (Tmp), the vapor pressure (Vap) and the wet day frequency (Wet).

Three other climate variables were computed using the relative extractable water (REW) computed with a water balance model developed by Wagner et al. (2011) calibrated at our study site and taking the daily precipitation from the CRU into account; this REW index takes values between 0 and 1 at our study site, corresponding to the available water for trees. This REW index is used to compute $\mathrm{Nb}_{\text {under }}$, the number of days under a REW threshold of 0.4 , which is the threshold recommended in Wagner et al. (2011); $A_{\text {under }}$, the area over the REW curve and under the threshold of 0.4 ; and $A_{\text {over }}$, the area situated under the REW curve and over the threshold of 0.95 . $\mathrm{Nb}_{\text {under }}$ and $A_{\text {under }}$ are built to be indicators of drought, while $A_{\text {over }}$ is related to soil water saturation. All climate variables are centered to allow an easier interpretation of the results.

\subsection{Model}

The model used in this study consists of a model coupling growth and mortality processes at the whole community scale. The model is build taking advantage of two preliminary studies where the growth (Hérault et al., 2011) and the mortality (Aubry-Kientz et al., 2013) sub-models were developed. The likelihood is computed using the distribution probability of mortality (Eqs. 3 and 4) and the computed growth rate (Eqs. 5 and 6). A vigor index is added into the mortality process, taking the past growth of the two previous years into account (Aubry-Kientz et al., 2015). We added the climate variables into the two processes to highlight the links between some climate drivers and one particular process. Because the final forest dynamic model was not linear, we build a Markov chain Monte Carlo algorithm under a Bayesian framework to infer the parameter posterior distributions. Growth and mortality processes were linked through tree vigor and are parameterized simultaneously. If tree $i$ stays alive, it grows at a growth rate $\mathrm{AGR}_{i, s, t}$, and its diameter $\mathrm{DBH}_{i, t-1}$ becomes $\mathrm{DBH}_{i, t}$. The joint model likelihood is then

$\prod_{t=1}^{n} f\left(\mathrm{DBH}_{i, t} \mid \mathrm{DBH}_{i, t-1}\right) \times\left(1-p_{i, s, t}\right)$ 
Table 1. The five functional traits used in the growth-mortality model. Descriptions of the traits, abbreviations used in this study and ranges observed in our data set.

\begin{tabular}{llll}
\hline Biological spectrum & Functional traits & Abbreviation & Range \\
\hline Life history & Maximum diameter $(\mathrm{m})$ & $\mathrm{DBH}_{\max }$ & {$[0.13 ; 1.11]$} \\
Life history & Maximum height $(\mathrm{dm})$ & $H_{\max }$ & {$[0.8 ; 5.6]$} \\
Wood economics & Trunk xylem density $\left(\mathrm{g} \mathrm{cm}^{-3}\right)$ & $\mathrm{WD}$ & {$[0.28 ; 0.91]$} \\
Leaf economics & Laminar toughness $(\mathrm{N})$ & Tough & {$[0.22 ; 11.4]$} \\
Leaf economics & Foliar $\delta^{13} \mathrm{C}$ composition $(\%)$ & $\delta^{13} \mathrm{C}$ & {$[-3.61 ;-2.62]$} \\
\hline
\end{tabular}

Table 2. The climate variables included in the growth-mortality model. Descriptions of the climate variables, abbreviations used in this study, ranges observed over 2 years in our data set, and sources used to compute the variables: CRU means that the variable is provided by the Climate Research Unit (Mitchell and Jones, 2005), and REW means that the variable is computed from the water balance model of Wagner et al. (2011).

\begin{tabular}{llll}
\hline Variable & Abbreviation & Range over 2 years & Source \\
\hline Cloud cover $(\%)$ & Cld & {$[56.8 ; 60.7]$} & CRU \\
Potential evapotranspiration $(\mathrm{mm})$ & Pet & {$[80.4 ; 84.4]$} & CRU \\
Precipitation $(\mathrm{mm})$ & Pre & {$[5486.3 ; 6207.3]$} & CRU \\
Daily mean temperature $\left({ }^{\circ} \mathrm{C}\right)$ & Tmp & {$[26.1 ; 26.9]$} & CRU \\
Vapor pressure $(\mathrm{HPA})$ & Vap & {$[705.7 ; 724.7]$} & $\mathrm{CRU}$ \\
Wet day frequency (days) & $\mathrm{Wet}$ & {$[385.2 ; 432.1]$} & $\mathrm{CRU}$ \\
Number of days with REW $<0.4$ & $\mathrm{Nb}$ under & {$[89 ; 170]$} & REW \\
Area over REW and $<0.4$ & $A_{\text {under }}$ & {$[9.1 ; 32.9]$} & REW \\
Area under REW and $>0.95$ & $A_{\text {over }}$ & {$[8.3 ; 12.5]$} & REW \\
\hline
\end{tabular}

if tree $i$ stays alive during the length of the studied period,

$p_{i, s, k} \times \prod_{t=1}^{k-1}\left(f\left(\mathrm{DBH}_{i, t} \mid \mathrm{DBH}_{i, t-1}\right) \times\left(1-p_{i, s, t}\right)\right)$

if tree $i$ dies between time $k-1$ and time $k$, where

- $f\left(\mathrm{DBH}_{i, t} \mid \mathrm{DBH}_{i, t-1}\right)$ is the probability density for a tree with diameter $\mathrm{DBH}_{i, t-1}$ at time $t-1$ to have a diameter $\mathrm{DBH}_{i, t}$ at time $t$; this quantity is used to compute the vigor estimator.

- $p_{i, s, t}$ is the probability of dying between time $t-1$ and time $t$, which depends on the vigor estimator, added in the model by multiplying the vigor estimator by $\theta_{1}$.

The model computes a mortality probability $p_{i, s, t}$ and a predicted growth rate $\widehat{\mathrm{AGR}}_{i, s, t-1}$.

$$
\begin{aligned}
& p_{i, s, t}=\operatorname{logit}^{-1}\left(\gamma_{1} \times \operatorname{clim}_{1}+\theta_{1} \times \text { Vigor }_{i, s, t}\right. \\
& +\theta_{2} \times \frac{\mathrm{DBH}_{i, s, t-1}}{\mathrm{DBH}_{\text {max }_{\mathrm{s}}}}+\theta_{3} \times\left(\frac{\mathrm{DBH}_{i, s, t-1}}{\mathrm{DBH}_{\text {max }_{\mathrm{s}}}}\right)^{2} \\
& \left.+\theta_{4} \times H_{\text {max }_{\mathrm{s}}}+\theta_{5} \times \mathrm{WD}_{\mathrm{s}}+\theta_{6} \times \mathrm{Tough}_{\mathrm{s}}\right)
\end{aligned}
$$

with

$\operatorname{Vigor}_{i, s, t}=\log \left(\frac{\mathrm{AGR}_{i, s, t-1}+1}{\widehat{\mathrm{AGR}}_{i, s, t-1}+1}\right)$, and

$$
\begin{aligned}
& \log \left(\widehat{\mathrm{AGR}}_{i, s, t-1}+1\right)=\left(\gamma_{2} \times \operatorname{clim}_{2}+\theta_{7} \times \mathrm{DBH}_{\text {max }_{\mathrm{s}}}\right. \\
& \left.+\theta_{8} \times \mathrm{WD}_{\mathrm{s}}+\theta_{9} \times H_{\mathrm{max}_{\mathrm{s}}}+\theta_{10} \times \delta 13 \mathrm{C}_{\mathrm{s}}\right) \\
& \times \exp \left(-\frac{1}{2}\left(\frac{\log \left(\frac{\mathrm{DBH}_{i, t-2}}{\theta_{11} \times \mathrm{DBH}_{\text {max }}}\right)}{\theta_{12} \times \mathrm{WD}_{\mathrm{s}}}\right)\right),
\end{aligned}
$$

and

$\log \left(\mathrm{AGR}_{i, s, t-1}+1\right)=\log \left(\widehat{\mathrm{AGR}}_{i, s, t-1}+1\right)+\varepsilon_{i}$,

with

$\varepsilon_{i} \sim \mathcal{N}\left(0, \theta_{13}\right)$,

where $p_{i, s, t}$ is the probability of dying of tree $i$ of species $s$ between time $t-1$ and $t$; $\widehat{\operatorname{AGR}}_{i, s, t-1}$ is the predicted growth between time $t-2$ and time $t-1$. $\mathrm{AGR}_{i, s, t-1}$ is the observed growth between time $t-2$ and time $t-1 ; \mathrm{DBH}_{\text {max }_{\mathrm{s}}}, H_{\text {max }_{\mathrm{s}}}$, $\mathrm{WD}_{\mathrm{s}}$, Tough $\mathrm{s}$ and $\delta 13 \mathrm{C}_{\mathrm{s}}$ are functional traits of species $s$ to which tree $i$ belongs (Table 1); $\theta_{1}, \theta_{2}, \cdots \theta_{13}$ are parameters to be estimated, and $\varepsilon_{i}$ is an individual error term following a normal distribution; $\gamma_{1}$ and $\gamma_{2}$ are the parameter vectors linking the climate predictors with the processes of mortality and growth respectively; $\operatorname{clim}_{1}$ and clim 2 are the vectors of climate predictors included in the processes of mortality and growth, respectively. 


\subsection{Variable selection}

To identify the different axes of variation of our climate data set and avoid including collinear variables in the model, we realized a principal component analysis (PCA) on the climate variables.

We included all climate variables one by one in each process of the model and computed the partial likelihood for each sub-model of growth or mortality we obtained. This provides a first result about the importance of each climate variable. Depending on these results and on their degree of collinearity from the PCA, we selected some climate variables and included them in the growth model and in the logit function of mortality.

\subsection{Model inference}

We implemented a Markov chain Monte Carlo algorithm to estimate the model parameters (Robert and Casella, 2004). A random walk was used as a proposal distribution to sample new values of parameters that were or were not selected, using the ratio of Metropolis-Hasting. Only standard deviation was sampled in an inverse-gamma posterior distribution with a Gibbs sampler. The functional traits used as demographical predictors were uncertain because botanical determination was incomplete for the older censuses, and not all values of functional traits were available for all species. We used the method developed in Aubry-Kientz et al. (2013) to handle these uncertainties. All the algorithms and statistical treatments were implemented with R software (Core Team, 2014).

\subsection{Functional trait and forest dynamic responses}

Functional traits were introduced in the final model with an interaction term by multiplying a climatic variable with a functional trait. We did not test all possible interactions but, based on results from a literature survey, we investigated biologically meaningful interactions only (Table 3 ). We included in the model an interaction between wood density and the drought estimator $A_{\text {under }}$, an interaction between $\mathrm{DBH}$ and $A_{\text {under }}$, and an interaction between $\mathrm{DBH}$ and precipitation Pre.

Species vary over 1 order of magnitude in their wood density (WD), ranging from 0.08 to $1.39 \mathrm{~g} \mathrm{~cm}^{3}$ (Iida et al., 2012), and the encountered range of wood density is particularly large in species-rich tropical rain forests (Chave et al., 2006, 2009). Wood density is a key functional trait because of its importance for mechanical stability, defense against herbivores, hydraulic conductivity, photosynthetic carbon gain and diameter growth rates of plants (Poorter et al., 2008). High wood density implies thin and short xylem vessels with small pit pores, which decrease the risk of embolism and cavitation. Trees with high wood density are then expected to be less sensitive to drought. The term $A_{\text {under }}$ multiplied by
(WD $\mathrm{max}_{\max }-\mathrm{WD}$ ) accounts for the effect of drought on trees with low wood density. This term is added in growth and mortality to test this effect (Table 3).

\section{Results}

\subsection{Variable selection}

The variable selection was realized using the literature, the PCA results, and the results of the univariate analysis.

\subsubsection{PCA}

The PCA underlines one principal axis, explaining $46 \%$ of the inertia and strongly negatively correlating with variables Tmp and Pet. The variables Wet and Cld are positively correlated with this axis, while Vap, $A_{\text {under }}$ and $\mathrm{Nb}_{\text {under }}$ are negatively correlated with this axis (Fig. 2). The second axis $(20 \%)$ is strongly negatively correlated with Pre and Area $_{\text {over. The third axis }}(12 \%)$ is essentially negatively correlated with $A_{\text {under }}$.

\subsubsection{Univariate analyses}

When the climate variables are included one by one in each model, all climate variables but precipitation (Pre) had an effect in the growth process, while only few had an effect in the mortality process (Table 4 ). The climates variables associated with the mortality process are Pre, $\mathrm{Nb}_{\text {under }}$ and $A_{\text {under }}$. In the growth model, $A_{\text {under }}$ is the best predictor according to the likelihood. In the mortality process, the best value of likelihood is obtained when $\mathrm{Nb}_{\text {under }}$ is included.

\subsubsection{Variable selection}

The Pet and temperature are indicators of the energy that the system receives and are expected to play a role in tree growth (Clark et al., 2003; Dong et al., 2012). These variables are strongly correlated $(r=0.8)$ and negatively correlated with the first axis of the PCA (Pet, $\mathrm{C}=-0.45$ and Tmp, $\mathrm{C}=-0.44$ ). This is not surprising, as Pet is computed using the temperature (Allen et al., 1998). As these two variables are strongly correlated, we finally included only temperature, which had a better likelihood score than Pet when it is included in the growth model. Neither Pet nor the temperature had an effect if included in the mortality process.

The second axis of the PCA is related to water saturation and is correlated with Pre $(\mathrm{C}=-0.68)$ and $A_{\text {over }}(\mathrm{C}=$ $-0.61)$. $A_{\text {over }}$ only had an effect when included in the growth process. However, both the effect size and the likelihood (Table 4) were the worst score obtained so that we did not include this variable in the final model. Concerning mortality, Pre had a clear effect (Fig. 3) and is thus included as a proxy of water saturation in the final mortality model. 
Table 3. Functional variability of expected responses to climate variables based on the literature. The functional variability is included in the model with an interaction term, i.e., multiplying a climatic variable with a given tree feature. Most hypotheses were not verified, but two significant effects are highlighted: large trees reduce their growth more during dry years, and trees with high wood density reduce their growth less during dry years.

\begin{tabular}{|c|c|c|c|c|c|}
\hline Process & Climatic variable & Tree feature & Expected effect based on literature & Reference & Result from this study \\
\hline \multirow{3}{*}{ growth } & $A_{\text {under }}$ & $\mathrm{DBH}$ & $\begin{array}{l}\text { Big trees reduce their } \\
\text { growth more during drought }\end{array}$ & Condit et al. (2004) & as expected \\
\hline & $A_{\text {under }}$ & $\mathrm{DBH}_{\max }-\mathrm{DBH}$ & $\begin{array}{l}\text { Small trees reduce their } \\
\text { growth more during drought }\end{array}$ & Hanson et al. (2001) & no result \\
\hline & $A_{\text {under }}$ & $\mathrm{WD}_{\max }-\mathrm{WD}$ & $\begin{array}{l}\text { Trees with high wood density reduce } \\
\text { their growth less during drought }\end{array}$ & Markesteijn (2010) & as expected \\
\hline \multirow{4}{*}{ mortality } & $A_{\text {under }}$ & $\mathrm{DBH}$ & $\begin{array}{l}\text { Big trees have a higher probability } \\
\text { of dying during drought }\end{array}$ & Nepstad et al. (2007) & no result \\
\hline & $A_{\text {under }}$ & $\mathrm{DBH}_{\max }-\mathrm{DBH}$ & $\begin{array}{l}\text { Small trees have a higher probability } \\
\text { of dying during drought }\end{array}$ & Hanson et al. (2001) & no result \\
\hline & $A_{\text {under }}$ & $\mathrm{WD}_{\max }-\mathrm{WD}$ & $\begin{array}{l}\text { Trees with high wood density } \\
\text { better resist drought }\end{array}$ & Phillips et al. (2009) & no result \\
\hline & Pre & DBH & $\begin{array}{l}\text { Big trees have higher probability of } \\
\text { falling during high precipitation }\end{array}$ & Ferry et al. (2010) & no result \\
\hline
\end{tabular}

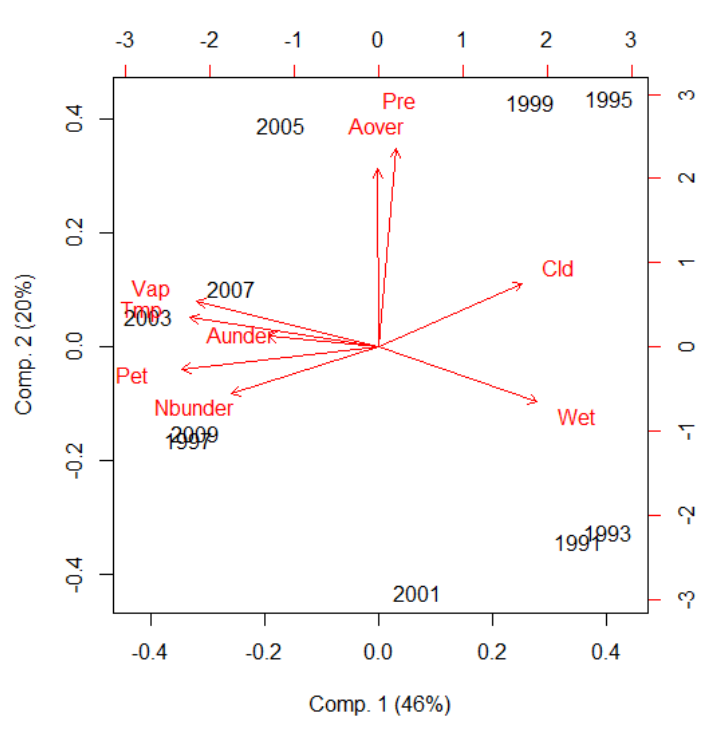

Figure 2. Results of the principal component analysis performed on climatic variables (red arrows) where census years are plotted to see the interannual climate variability in the Paracou data set. The first axis ( $46 \%$ of variance) is mainly driven by the variables Pet (potential evapotranspiration) and tmp (temperature). The second axis (20\% of variance) is mainly driven by $A_{\text {over (area over REW and }}$ $<0.4$ ) and Pre (precipitation) and may be interpreted as an axis representing soil water saturation. The third axis (not represented here, $13 \%$ of variance), is mainly driven by $A_{\text {under }}$ (area under REW and $>0.95$ ), which is an indicator of water stress.

The third axis of the PCA is strongly correlated with the drought estimator $A_{\text {under, }}$, which is the best climate driver of growth regarding the likelihood and the effect size. $A_{\text {under }}$ also had an effect on the mortality process and is finally included in the two processes in the final model.
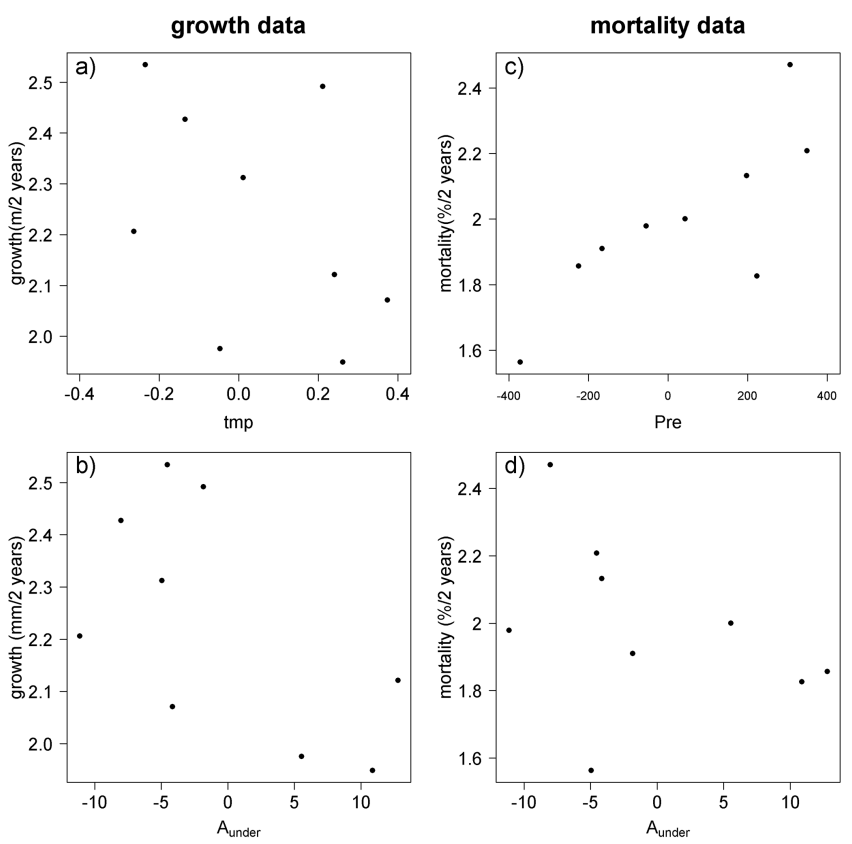

Figure 3. Climatic drivers of tree dynamics. Observed mean growth (mm per 2 years) is plotted against temperature (a) and against the water stress (b). Observed mortality rate (proportion per 2 years) is plotted in abscissa against precipitation (c) and against the water stress (d).

\subsection{Full model inference}

The growth trajectory was adjusted by a size-dependent diameter growth model (Fig. 4). Parameters linking the maximal growth to the functional traits $\mathrm{DBH}_{\max }, \mathrm{WD}, H_{\max }$ and $\delta^{13} \mathrm{C}$ have similar values and interpretations to Hérault et al. 
Table 4. Results of the estimation process for each demographic parameter associated with the climate variables. The variables were added in the growth process or in the mortality process in a univariate way, i.e., one by one, and all parameters were estimated using a MetropolisHastings algorithm. Effect sizes were estimated by multiplying the amplitude of the observed variable to the absolute value of the estimator. Only significant results are represented.

\begin{tabular}{lrrr|rrr}
\hline & \multicolumn{2}{c}{ Growth } & \multicolumn{3}{c}{ Mortality } \\
\hline Variable & Estimator & $95 \%$ CI & Effect size & Estimator & $95 \%$ CI & Effect size \\
\hline Cld & 0.027 & {$[0.025 ; 0.029]$} & 0.10 & - & - & - \\
Pet & -0.033 & {$[-0.035 ;-0.031]$} & 0.13 & - & - & - \\
Pre & - & - & - & 0.00035 & {$[0.00022 ; 0.00048]$} & 0.25 \\
Tmp & -0.17 & {$[-0.25 ;-0.06]$} & 0.13 & - & - & - \\
Vap & -0.0048 & {$[-0.0052 ;-0.0043]$} & 0.09 & - & - & - \\
Wet & 0.0010 & {$[0.0006 ; 0.0014]$} & 0.05 & - & - & 0.21 \\
Nb & -0.0017 & {$[-0.0023 ;-0.0011]$} & 0.14 & -0.0026 & {$[-0.0035 ;-0.0018]$} & 0.18 \\
$A_{\text {under }}$ & -0.0060 & {$[-0.0076 ;-0.0042]$} & 0.14 & -0.0075 & {$[-40.0113 ;-0.0039]$} & - \\
$A_{\text {over }}$ & -0.013 & {$[-0.015 ;-0.011]$} & 0.05 & - & - & - \\
\hline
\end{tabular}

(2011); that is, maximum growth rates increase with increasing $\mathrm{DBH}_{\max }$, and decreasing WD, $H_{\max }$ and $\delta^{13} \mathrm{C}$ (Table 5). Maximum growth rate is attained for a tree diameter equal to $0.794 \times \mathrm{DBH}_{\max }$. The parameters linking the probability of mortality to $H_{\max }$, WD and Tough converged around negative values, meaning that the probability of dying is lower when the tree is high, has a high wood density and/or high laminar toughness. The drought estimator $\left(A_{\text {under }}\right)$ converged to negative values in the growth and mortality processes; thus growth and mortality computed at our biannual timescale are lower when the drought estimator $A_{\text {under }}$ is higher. The parameter linking mortality with precipitation (Pre) is positive. This finding implies that mortality rate is higher during 2-year timescale with high precipitation. In our data set, the highest total precipitation was, albeit non-significantly, rather related to the highest proportion of tree-fall deaths (Fig. 5). The parameter linking temperature (tmp) and growth takes negative values; thus growth values are lower during the warmest periods.

\subsection{Functional variability of responses}

In the growth process, interaction between $\left(\mathrm{WD}_{\max }-\mathrm{WD}\right)$ and drought is negative (Table 3), implying that trees with lower WD are more sensitive to drought and reduce their growth more. Moreover, interactions linking the current diameter and drought are also negative; thus larger trees are more sensitive to drought and reduce their growth more compared to smaller trees. None of the interaction terms included in the mortality process had an effect (Table 3 ).

\section{Discussion}

In this study, we questioned the importance of the climate drivers of tropical forest dynamics by using a community growth-mortality modeling framework. First, one can note that few climate variables had a univariate effect when included in the mortality process, while almost all had a univariate effect in the growth process. However, the magnitude of the impact of climate variables is stronger in the mortality process (observed mortality rate varying between 1.6 and $2.5 \%$ of mortality per 2 years, while observed growth rates vary between 1.9 and $2.5 \mathrm{~mm}$ per 2 years, Fig. 3). Next, we developed Bayesian algorithms to infer the multivariate nonlinear model and select the best predictors with a great flexibility. We found that drought decreased annual growth and mortality rates, high precipitation through soil water saturation increased mortality rates and high temperature decreased growth (Fig. 4). We confirmed that the vigor index is negatively related to mortality: trees that grow more than expected have a lower probability of dying, and trees with lower-thanexpected growth have a higher probability of dying. Moreover, the posterior values for obtained the functional trait parameters are coherent with results of Hérault et al. (2011) and Aubry-Kientz et al. (2013), increasing our confidence in (i) the developed algorithm and (ii) the biological determinism of the ecological processes we want to model. This confirms that the functional trait-based approach could be successfully used to predict climate-induced tree dynamics in highly diverse tropical forests for which taxonomic data may be lacking but functional trait data are available. A limited number of interactions between climate variables and functional traits was tested because of our selection of three climate predictors. One can argue that some climatic variables that were disregarded in the first selection step would increase the likelihood if included in interactions with a functional trait. This pathological case is very improbable (Wagner et al., 2014) and will necessitate an impractical amount of computational time to be tested. 
Table 5. Result of the estimation process for the final model. The Metropolis-Hastings algorithm was run with 2000 iterations, burning of 1000 iterations, thinning of 10 iterations. In the growth process, variables with * are included in the exponential kernel.

\begin{tabular}{llrrr}
\hline Process & Variable & Parameter & Estimator & $95 \%$ credibility interval \\
\hline \multirow{6}{*}{ mortality } & vigor & $\theta_{1}$ & -0.52 & {$[-0.56 ;-0.49]$} \\
& DBH/DBH $H_{\max }$ & $\theta_{2}$ & -0.61 & {$[-1.03 ;-0.30]$} \\
& $\left(\mathrm{DBH} / \mathrm{DBH}_{\max }\right)^{2}$ & $\theta_{3}$ & 0.48 & {$[0.30 ; 0.77]$} \\
& $H_{\max }$ & $\theta_{4}$ & -0.40 & {$[-0.44 ;-0.36]$} \\
& WD & $\theta_{5}$ & -2.8 & {$[-3.0 ;-2.5]$} \\
& Tough & $\theta_{6}$ & -0.36 & {$[-0.41 ;-0.30]$} \\
& Pre & $\gamma_{1}$ & 0.00032 & {$[0.00021 ; 0.00044]$} \\
& $A_{\text {under }}$ & $\gamma_{1}$ & -0.0053 & {$[-0.0087 ;-0.0023]$} \\
\hline \multirow{6}{*}{ growth } & $\mathrm{DBH}_{\max }$ & $\theta_{7}$ & 1.81 & {$[1.78 ; 1.84]$} \\
& WD & $\theta_{8}$ & -0.40 & {$[-0.44 ;-0.35]$} \\
& $H_{\max }$ & $\theta_{9}$ & -0.063 & {$[-0.070 ;-0.057]$} \\
& $\delta^{13} \mathrm{C}$ & $\theta_{10}$ & -0.21 & {$[-0.22 ;-0.20]$} \\
& $\mathrm{DBH} H_{\max }$ & $\theta_{11}$ & 0.80 & {$[0.76 ; 0.84]$} \\
& WD* & $\theta_{12}$ & 2.36 & {$[2.27 ; 2.44]$} \\
& tmp & $\gamma_{2}$ & -0.067 & {$[-0.093 ;-0.045]$} \\
& $A_{\text {under }}$ & $\gamma_{2}$ & -0.0049 & {$[-0.0054 ;-0.0044]$} \\
& $\varepsilon$ & $\gamma_{13}$ & 0.579 & {$[0.576 ; 0.583]$} \\
\hline
\end{tabular}

\subsection{Water stress}

The water stress during the dry season, estimated with $A_{\text {under, }}$, negatively impacts the growth and mortality processes. Trees will thus grow less quickly and have a lower probability of dying during 2-year periods with the most intense dry seasons. The reduction of growth is expected, and has many ecophysiological causes. Indeed, water is essential for sap fluxes and for photosynthesis efficiency. The reduction of growth is furthermore linked with the current DBH and the species' wood density (Table 3). Big trees are more sensitive to water stress than small trees. This was expected in light of the results obtained after rainfall exclusion (da Costa et al., 2010). Indeed, maintenance costs are higher for big trees, making these trees more vulnerable to the driest periods. Regarding the wood density, species with high values are more resistant to drought. This is consistent with our hypothesis that high wood density implies thin and short xylem vessels and thus decreases the risk of embolism and cavitation. As the ability of trees to recover from periods of sustained drought is strongly related to their embolism resistance (Choat et al., 2012), a tree with high wood density will be more able to maintain growth during dry years. For similar reasons, we expected a positive impact of $A_{\text {under }}$ on mortality rates. Experimental trough-fall exclusions conducted in Tapajós and Caxiuanã indeed demonstrated that $50 \%$ rainfall exclusion led to very high mortality rates (Nepstad, 2002). Our results show no positive effect of drought intensity on mortality rates (Table 4) and look contradictory to Nepstad (2002). However, the natural variability of the drought intensity (total rainfall from 5486 to $6207 \mathrm{~mm}$ ) in our data set is hardly comparable to the experimental $50 \%$ reduction in total rain- fall. Moreover, our modeling framework prevented us from seeing long-term effects induced by repeated drought events because the drought variable values depend only on the last 2 -year climate. One may also expect that standing death is more frequent during the driest periods but, when plotting tree mode of death against drought estimator $\left(A_{\text {under }}\right)$, no evidence was observed for a potential trend (Fig. 5). To conclude, our results confirmed that the relationship between drought and mortality may be challenging to estimate and to link with their underlying causes at an inter-annual timescale.

\subsection{Water saturation}

Water saturation Pre had a strong effect on mortality; mortality rate varied between 1.5 and $2 \%$ per 2 years with increasing total precipitation. This is consistent with the hypothesis that trees are more vulnerable when the soil is water saturated. In the Paracou forest, about half of tree deaths are due to standing death and half to tree fall. This ratio looks, albeit non-significantly $\left(R^{2}=0.61, P=0.08\right.$ because of the low number of observations; $n=9$ ), linked with total precipitation. The highest total precipitation led to the highest proportion of tree-fall deaths (Fig. 5). This confirms the observation of Ferry et al. (2010) and the hypothesis that waterlogged soils in space or in time are risky for trees. Moreover, during the rainy season, strong rainfall events often come with strong winds that may accelerate this process (Toledo et al., 2011). Studies observing a relationship between tree mortality and excess of water in the soil primarily focus on geographical variation (Ferry et al., 2010; de Toledo et al., 2012) and conclude that excess water in the soil restricts root establishment because productivity of fine roots and rooting 

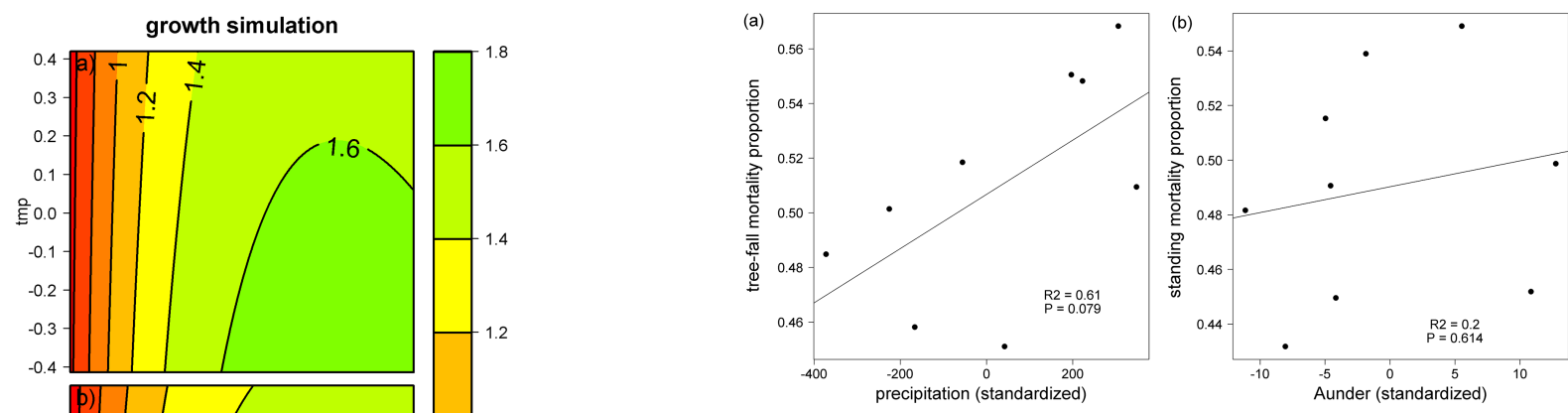

Figure 5. Proportion of dead trees caused by tree fall plotted against the climate variable Pre (a) and proportion of dead trees caused by standing death plotted against the climate variable $A_{\text {under }}(\mathbf{b})$. About $50 \%$ of tree deaths are tree fall; this proportion is quite higher but not significant ( $F$ statistic test, $P=0.079$ ) during 2-year periods with high precipitation. No significant correlation $(F$ statistic test, $P=0.814$ ) between the mode of death and the drought intensity $A_{\text {under }}$ was noted.

depth are generally low in sandy soils and soils with high moisture content. Our results highlight that the time variation in soil water saturation is also very important and should be reassessed.

\subsection{Temperature}

Temperature is identified as predictor of trees' decreasing growth. As the temperature rises, the velocity of reacting molecules increases, leading to more rapid reaction rates but also to damage of the tertiary structures of the enzymes and reduced enzyme activity and reaction rates (Fitter and Hay, 2001; Lloyd and Farquhar, 2008). These two processes are responsible for a bell-shaped curve of growth response to temperature (Fitter and Hay, 2001). Temperature can affect photosynthesis through modulation of the rates of activity of photosynthetic enzymes and the electron transport chain, and in a more indirect manner, through leaf temperatures defining the magnitude of the leaf-to-air vapor pressure difference, a key factor influencing stomatal conductances (Lloyd and Farquhar, 2008). In tropical forests, as temperatures are already high, rising temperatures may imply lower growth, consistent with results from Clark et al. (2003).

This temperature effect may become the most problematic for tropical forest dynamics, considering the rising temperatures that are predicted, with a great degree of certainty, by climate models for the next century (Stocker et al., 2013). Indeed, as temperature was identified as a strong predictor of growth, all else being equal, averaged community growth and forest productivity may consequently decrease in time. This decline in productivity in time is perhaps what we are starting to see throughout the Amazon (Brienen et al., 2015). As no consensus has been reached yet, additional studies using regular inventories are urgently needed (Reed et al., 2012; Corlett, 2011) to explain the conflicting patterns of the 

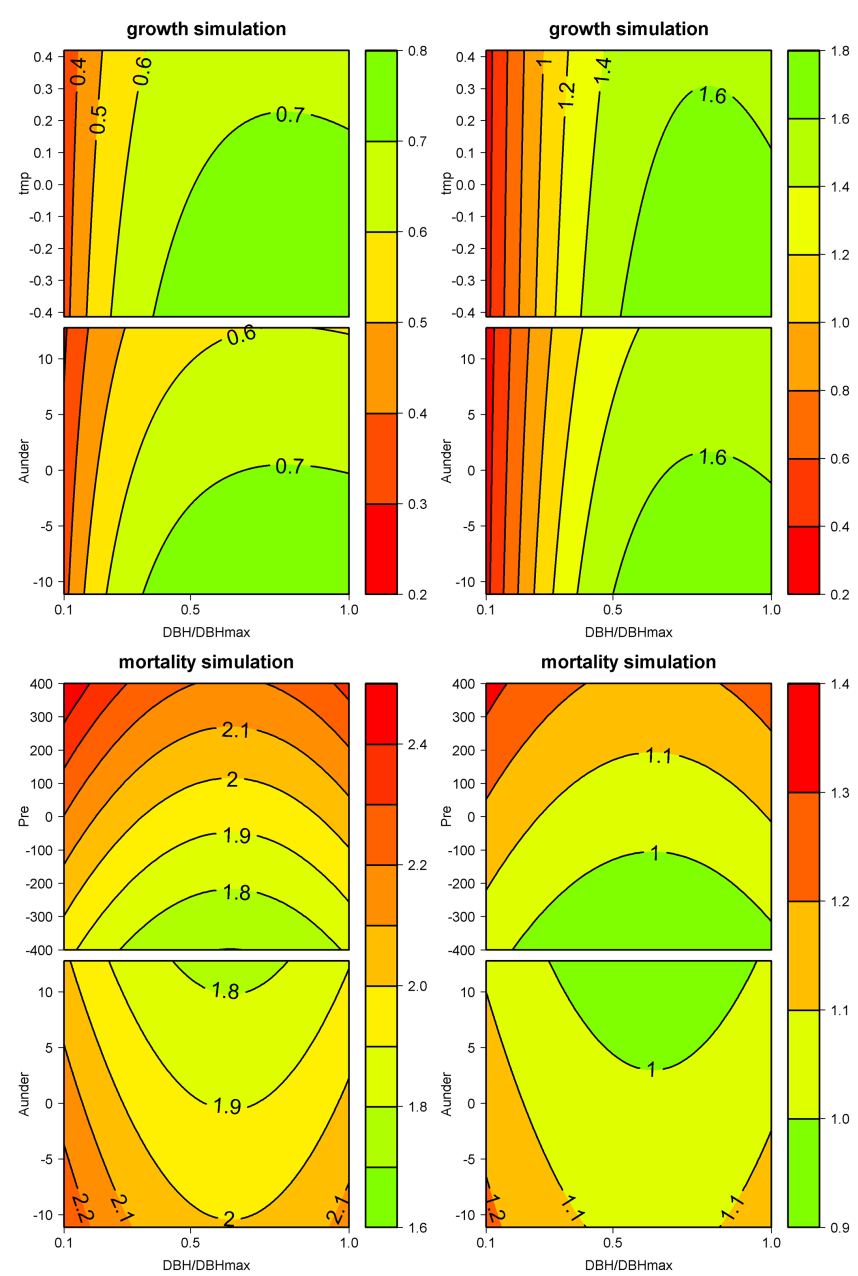

Figure 6. Predictions of growth and mortality depending of climatic drivers for Oxandra asbeckii and Hevea guianensis. Simulations are made using the functional traits values of the species Oxandra asbeckii (left) and Hevea guianensis (right). Growth (in mm per 2 years) is computed with varying temperature (first line) and with varying water stress (second line) and is plotted against the ontogeny $\left(\mathrm{DBH} / \mathrm{DBH}_{\max }\right)$. Growth rises with reduced temperature and reduced water stress. This is more noticeable for large values of $\mathrm{DBH} / \mathrm{DBH}_{\max }$, which means large, old trees. Mortality (\% per 2 years) is computed with varying precipitation (third line) and with varying water stress (fourth line) and is plotted against the ontogeny $\left(\mathrm{DBH} / \mathrm{DBH}_{\max }\right)$. Mortality rate rises with rising precipitation and reduced water stress.

temperature effect found in the extant literature (Dong et al., 2012). Finally, we need to acknowledge that we do not know much about how forest dynamics will behave in the next century under temperature conditions that will be so different from what is actually observed. In this context, manipulative warming experiments are increasingly vital to better predict the future of tropical forest dynamics (Cavaleri et al., 2015).

\section{Conclusions}

Global climate models converge to simulate, at least for the Amazonian region, a change in precipitation regime and temperature conditions over the coming decades (Malhi et al., 2009). Drought is expected to become longer and stronger in the future (Joetzjer et al., 2013). and the temperature will continue rising drastically during the next century (Stocker et al., 2013). Our modeling framework allows us to study inter-annual variations of climatic variables and identify which of these climatic variables are the key drivers of tropical forest dynamics. Drought, precipitation and temperature were highlighted as strong drivers of tree growth and/or mortality. Drought decreased annual growth and mortality rates, high temperature decreased growth and high precipitation events increased mortality rates. Moreover, we demonstrated best resistance to drought for trees with high wood density and for trees with small current diameters, giving us some possible indications on the future composition of a tropical forest where droughts are becoming more frequent. In light of these results, raising awareness of the current impacts of climate changes on tropical forest dynamics is urgent. 
Appendix A: Growth and mortality simulations for Oxandra and Hevea

Simulations presented in Fig. 4 are realized using median values for tree functional traits. These median values do not have any ecological meaning, and the figure was realized only to show how climatic drivers impact the tree growth and mortality in reality (Fig. 3) and in our model (Fig. 4). To show more realistic simulations, the same patterns are plotted for two species that differ in their ecological strategies in Fig. 6. The first column shows the simulated dynamics of Oxandra asbeckii, a relatively small tree. The second column shows the simulated dynamics of Hevea guianensis, which is a canopy tree reaching heights of $50 \mathrm{~m}$ and which has a low wood density. These two strongly contrasting species show two different growth and mortality rates, although the effects of climatic drivers stay the same. 
Acknowledgements. Funding came from the Climfor Project (Fondation pour la Recherche sur la Biodiversité) and from the Guyasim Project (European structural funding, PO-feder). The funders had no role in study design, data collection and analysis, decision to publish or preparation of the manuscript. This work also benefited from an "Investissement d'Avenir" grant managed by the Agence Nationale de la Recherche (CEBA, ref ANR-10-LABX-0025) and from a grant from the Centre de Coopération Internationale en Recherche Agronomique pour le Développement.

Edited by: K. Thonicke

\section{References}

Allen, C. D., Macalady, A. K., Chenchouni, H., Bachelet, D., McDowell, N., Vennetier, M., Kitzberger, T., Rigling, A., Breshears, D. D., Hogg, E. T. H., Gonzalez, P., Fensham, R., Zhang, Z., Castro, J., Demidova, N., Lim, J.-H. H., Allard, G., Running, S. W., Semerci, A., and Cobb, N.: A global overview of drought and heat-induced tree mortality reveals emerging climate change risks for forests, Forest Ecol. Manag., 259, 660684, doi:10.1016/j.foreco.2009.09.001, 2010.

Allen, R. G., Pereira, L. S., Raes, D., and Smith, M.: Crop evapotranspiration - Guidelines for computing crop water requirements - FAO Irrigation and drainage paper 56, 1-15, 1998.

Aragão, L. E. O. C., Malhi, Y., Roman-Cuesta, R. M., Saatchi, S., Anderson, L. O., and Shimabukuro, Y. E.: Spatial patterns and fire response of recent Amazonian droughts, Geophys. Res. Lett., 34, L07701, doi:10.1029/2006GL028946, 2007.

Aubry-Kientz, M., Hérault, B., Ayotte-Trépanier, C., Baraloto, C., and Rossi, V.: Toward trait-based mortality models for tropical forests., PloS One, 8, e63678, doi:10.1371/journal.pone.0063678, 2013.

Aubry-Kientz, M., Rossi, V., Boreux, J.-J., and Hérault, B.: A joint individual-based model coupling growth and mortality reveals that tree vigor is a key component of tropical forest dynamics, Ecol. Evolut., 5, 2457-2465, doi:10.1002/ece3.1532, 2015.

Baraloto, C., Paine, C. E. T., Patiño, S., Bonal, D., Hérault, B., and Chave, J.: Functional trait variation and sampling strategies in species-rich plant communities, Funct. Ecol., 24, 208-216, doi:10.1111/j.1365-2435.2009.01600.x, 2010a.

Baraloto, C., Paine, C. E. T., Poorter, L., Beauchene, J., Bonal, D., Domenach, A. M., Hérault, B., Patino, S., Roggy, J. C., and Chave, J.: Decoupled leaf and stem economics in rain forest trees, Ecol. Lett., 13, 1338-1347, 2010 b.

Brando, P. M., Nepstad, D. C., Davidson, E. A., Trumbore, S. E., Ray, D., and Camargo, P.: Drought effects on littefall, wood production and belowground carbon cycling in an Amazon Forest: result of a throughfall reduction experiment, Philos. T. R. Soc. A, 363, 1839-1848, doi:10.1098/rstb.2007.0031, 2008.

Brando, P. M., Goetz, S. J., Baccini, A., Nepstad, D. C., Beck, P. S. A., and Christman, M. C.: Seasonal and interannual variability of climate and vegetation indices across the Amazon., P. Natl. Acad. Sci. USA, 107, 14685-14690, doi:10.1073/pnas.0908741107, 2010.

Brienen, R. J. W., Phillips, O. L., Feldpausch, T. R., et al.: Longterm decline of the Amazon carbon sink, Nature, 519, 344-348, doi:10.1038/nature14283, 2015.
Cavaleri, M., Reed, S., Smith, W., and Wood, T.: Urgent need for warming experiments in tropical forests, Glob. Change Biol., 111, doi:10.1111/gcb.12860, 21, 2111-2121, 2015.

Chave, J., Muller-Landau, H. C., Baker, T. R., Easdale, T. a., ter Steege, H., and Webb, C. O.: Regional and phylogenetic variation of wood density across 2456 Neotropical tree species, Ecological applications: a publication of the Ecological Society of America, 16, 2356-67, 2006.

Chave, J. J., Coomes, D., Jansen, S., Lewis, S. L., Swenson, N. G., and Zanne, A. E.: Towards a worldwide wood economics spectrum., Ecol. Lett., 12, 351-66, doi:10.1111/j.14610248.2009.01285.x, 2009.

Choat, B., Jansen, S., Brodribb, T. J., Cochard, H., Delzon, S., Bhaskar, R., Bucci, S. J., Feild, T. S., Gleason, S. M., Hacke, U. G., Jacobsen, A. L., Lens, F., Maherali, H., Martínez-Vilalta, J., Mayr, S., Mencuccini, M., Mitchell, P. J., Nardini, A., Pittermann, J., Pratt, R. B., Sperry, J. S., Westoby, M., Wright, I. J., and Zanne, A. E.: Global convergence in the vulnerability of forests to drought, Nature, 491, 752-5, doi:10.1038/nature11688, 2012.

Clark, D. A., Piper, S. C., Keeling, C. D., and Clark, D. B.: Tropical rain forest tree growth and atmospheric carbon dynamics linked to interannual temperature variation during 1984-2000., P. Natl. Acad. Sci. USA, 100, 5852-5857, doi:10.1073/pnas.0935903100, 2003.

Clark, D. B., Clark, D. A., and Oberbauer, S. F.: Annual wood production in a tropical rain forest in NE Costa Rica linked to climatic variation but not to increasing $\mathrm{CO}_{2}$, Glob. Change Biol., 16, 747-759, doi:10.1111/j.1365-2486.2009.02004.x, 2010.

Condit, R.: Research in large, long-term tropical forest plots, Trends in Ecol. Evolut., 10, 18-22, doi:10.1016/S0169-5347(00)889557, 1995.

Condit, R., Aguilar, S., Hernandez, A., Perez, R., Lao, S., Angehr, G., Hubbell, S. P., and Foster, R. B.: Tropical forest dynamics across a rainfall gradient and the impact of an El Nino dry season, J. Trop. Ecol., 20, 51-72, 2004.

Core Team, R.: R: A Language and Environment for Statistical Computing, http://www.r-project.org/ (last access: 29 September 2015), 2014.

Corlett, R. T.: Impacts of warming on tropical lowland rainforests, Trends in Ecol. Evolut., 26, 606-613, doi:10.1016/j.tree.2011.06.015, 2011.

da Costa, A. C. L., Galbraith, D., Almeida, S., Portela, B. T. T., da Costa, M., Silva Junior, J. a. D. A., Braga, A. P., de Gonçalves, P. H. L., de Oliveira, A. a. R., Fisher, R., Phillips, O. L., Metcalfe, D. B., Levy, P., and Meir, P.: Effect of 7 yr of experimental drought on vegetation dynamics and biomass storage of an eastern Amazonian rainforest., New Phytol., 187, 579-91, doi:10.1111/j.1469-8137.2010.03309.x, 2010.

de Toledo, J. J., Magnusson, W. E., Castilho, C. V., and Nascimento, H. E. M.: Tree mode of death in Central Amazonia: Effects of soil and topography on tree mortality associated with storm disturbances, Forest Ecol. Manag., 263, 253-261, doi:10.1016/j.foreco.2011.09.017,, 2012.

Dong, S. X., Davies, S. J., Ashton, P. S., Bunyavejchewin, S., Supardi, M. N. N., Kassim, A. R., Tan, S., and Moorcroft, P. R.: Variability in solar radiation and temperature explains observed patterns and trends in tree growth rates across four tropical forests., P. Roy. Soc. B-Biol. Sci., 279, 3923-31, doi:10.1098/rspb.2012.1124, 2012. 
Feng, X., Porporato, A., and Rodriguez-Iturbe, I.: Changes in rainfall seasonality in the tropics, Nature Climate Change, 3, 811815, doi:10.1038/nclimate1907,2013.

Ferry, B., Morneau, F., Bontemps, J. D., Blanc, L., and Freycon, V.: Higher treefall rates on slopes and waterlogged soils result in lower stand biomass and productivity in a tropical rain forest, $\mathrm{J}$. Ecol., 98, 106-116, 2010.

Fitter, A. H. and Hay, R. K.: Environmental physiology of plants, Academic P edn., 367 pp., London, 2001.

Grogan, J. and Schulze, M.: The Impact of Annual and Seasonal Rainfall Patterns on Growth and Phenology of Emergent Tree Species in Southeastern Amazonia, Brazil, Biotropica, 44, 331340, 2012

Hanson, P. J., Todd, D. E., and Amthor, J. S.: A six-year study of sapling and large-tree growth and mortality responses to natural and induced variability in precipitation and throughfall, Tree Physiol., 21, 345-58, 2001.

Herault, B., Ouallet, J., Blanc, L., Wagner, F., and Baraloto, C.: Growth responses of neotropical trees to logging gaps, J. Appl. Ecol., 47, 821-831, doi:10.1111/j.1365-2664.2010.01826.x, 2010.

Hérault, B., Bachelot, B., Poorter, L., Rossi, V., Bongers, F., Chave, J., Paine, C. E. T., Wagner, F., and Baraloto, C.: Functional traits shape ontogenetic growth trajectories of rain forest tree species, J. Ecol., 99, 1431-1440, doi:10.1111/j.1365-2745.2011.01883.x, 2011.

Iida, Y., Poorter, L., Sterck, F. J., Kassim, A. R., Kubo, T., Potts, M. D., and Kohyama, T. S.: Wood density explains architectural differentiation across 145 co-occurring tropical tree species, Funct. Ecol., 26, 274-282, 2012.

Joetzjer, E., Douville, H., Delire, C., and Ciais, P.: Present-day and future Amazonian precipitation in global climate models: CMIP5 versus CMIP3, Climate Dynamics, 41, 2921-2936, doi:10.1007/s00382-012-1644-1, 2013.

Lloyd, J. and Farquhar, G. D.: Effects of rising temperatures and $\left[\mathrm{CO}_{2}\right]$ on the physiology of tropical forest trees., Philos. T. R. Soc. B, 363, 1811-7, doi:10.1098/rstb.2007.0032, 2008.

Malhi, Y., Aragão, L. E. O. C., Galbraith, D., Huntingford, C., Fisher, R., Zelazowski, P., Sitch, S., Mcsweeney, C., and Meir, P.: Exploring the likelihood and mechanism of a climate-changeinduced dieback of the Amazon rainforest, P. Natl. Acad. Sci. USA, 106, 20610-20615, 2009.

Markesteijn, L.: Drought tolerance of tropical tree species; Functional Traits, Trade-offs and Species Distribution, Ph.D. thesis, Wageningen University, 204 pp., 2010.

Mitchell, T. D. and Jones, P. D.: An improved method of constructing a database of monthly climate observations and associated high-resolution grids, Int. J. Climatol., 25, 693-712, doi:10.1002/joc.1181, 2005.

Nepstad, D. C.: The effects of partial throughfall exclusion on canopy processes, aboveground production, and biogeochemistry of an Amazon forest, J. Geophys. Res., 107, 8085, doi:10.1029/2001JD000360, 2002.

Nepstad, D. C., Tohver, I. M., Ray, D., Moutinho, P., and Cardinot, G.: Mortality of large trees and lianas following experimental drought in an Amazon forest, Ecology, 88, 2259-69, 2007.

Phillips, O. L., Aragao, L., Lewis, S. L., Fisher, J. B., Lloyd, J., Lopez-Gonzalez, G., Malhi, Y., Monteagudo, A., Peacock, J., Quesada, C. A., van der Heijden, G., Almeida, S., Amaral, I.,
Arroyo, L., Aymard, G., Baker, T. R., Banki, O., Blanc, L., Bonal, D., Brando, P., Chave, J., de Oliveira, A. C. A., Cardozo, N. D., Czimczik, C. I., Feldpausch, T. R., Freitas, M. A., Gloor, E., Higuchi, N., Jimenez, E., Lloyd, G., Meir, P., Mendoza, C., Morel, A., Neill, D. A., Nepstad, D., Patino, S., Penuela, M. C., Prieto, A., Ramirez, F., Schwarz, M., Silva, J., Silveira, M., Thomas, A. S., ter Steege, H., Stropp, J., Vasquez, R., Zelazowski, P., Davila, E. A., Andelman, S., Andrade, A., Chao, K.j. J., Erwin, T., Di Fiore, A., Honorio, E., Keeling, H., Killeen, T. J., Laurance, W. F., Cruz, A. P. n., Pitman, N. C. A., Vargas, P. N. n., Ramirez-Angulo, H., Rudas, A., Salamao, R., Silva, N., Terborgh, J., Torres-Lezama, A., Aragão, L. E. O. C., Lópezgonzález, G., Heijden, G. V. D., Bánki, O., Cristina, A., Oliveira, A. D., Jiménez, E., Patiño, S., Peñuela, M. C., Ramírez, F., Steege, H., Vásquez, R., Dávila, E. A., Fiore, A. D., C, E. H., Ramírez-angulo, H., and Salamão, R.: Drought sensitivity of the Amazon Rainforest, Science, 323, 1344-1347, 2009.

Phillips, O. L., van der Heijden, G., Lewis, S. L., López-González, G., Aragão, L. E. O. C., Lloyd, J., Malhi, Y., Monteagudo, A., Almeida, S., Dávila, E. A., Amaral, I., Andelman, S., Andrade, A., Arroyo, L., Aymard, G., Baker, T. R., Blanc, L., Bonal, D., de Oliveira, A. C. A., Chao, K. J., Cardozo, N. D., da Costa, L., Feldpausch, T. R., Fisher, J. B., Fyllas, N. M., Freitas, M. A., Galbraith, D., Gloor, E., Higuchi, N., Honorio, E., Jiménez, E., Keeling, H., Killeen, T. J., Lovett, J. C., Meir, P., Mendoza, C., Morel, A., Vargas, P. N. n., Patiño, S., Peh, K. S. H., Cruz, A. P. n., Prieto, A., Quesada, C. a., Ramírez, F., Ramírez, H., Rudas, A., Salamão, R., Schwarz, M., Silva, J., Silveira, M., Ferry Slik, J. W., Sonké, B., Thomas, A. S., Stropp, J., Taplin, J. R. D., Vásquez, R., and Vilanova, E.: Drought-mortality relationships for tropical forests, New Phytol., 187, 631-646, doi:10.1111/j.1469-8137.2010.03359.x, 2010.

Poorter, L., Wright, S. J., Paz, H., Ackerly, D. D., Condit, R., IbarraManríquez, G., Harms, K. E., Licona, J.-C., Martínez-Ramos, M., Mazer, S. J., Muller-Landau, H. C., Peña Claros, M., Webb, C. O., and Wright, I. J.: Are functional traits good predictors of demographic rates? Evidence from five Neotropical forests, Ecology, 89, 1908-1920, 2008.

Reed, S. C., Wood, T. E., and Cavaleri, M. A.: Tropical forests in a warming world, New Phytol., 193, 27-29, 2012.

Robert, C. P. and Casella, G.: Monte Carlo statistical methods, Springer, 2 edn., 649 pp., 2004.

Rüger, N., Wirth, C., Wright, S. J., and Condit, R.: Functional traits explain light and size response of growth rates in tropical tree species, Ecology, 93, 2626-2636, 2012.

Slik, J. W. F.: El Niño droughts and their effects on tree species composition and diversity in tropical rain forests, Oecologia, 141, 114-120, doi:10.1007/s00442-004-1635-y, 2004.

Stocker, T., Qin, D., Plattner, G., Tignor, M., Allen, S., Boschung, J., Nauels, A., Xia, Y., Bex, B., and Midgley, B.: IPCC, 2013: climate change 2013: the physical science basis. Contribution of working group I to the fifth assessment report of the intergovernmental panel on climate change, Cambridge University Press, 1535 pp., 2013.

Tan, Z. H., Cao, M., Yu, G. R., Tang, J. W., Deng, X. B., Song, Q. H., Tang, Y., Zheng, Z., Liu, W. J., Feng, Z. L., Deng, Y., Zhang, J. L., Liang, N., and Zhang, Y. P.: High sensitivity of a tropical rainforest to water variability: Evidence from 10 years 
of inventory and eddy flux data, J. Geophys. Res.-Atmos., 118, 9393-9400, doi:10.1002/jgrd.50675, 2013.

Toledo, M., Poorter, L., Peña Claros, M., Alarcón, A., Balcázar, J., Leaño, C., Licona, J. C., Llanque, O., Vroomans, V., Zuidema, P. A., and Bongers, F.: Climate is a stronger driver of tree and forest growth rates than soil and disturbance, J. Ecol., 99, 254264, doi:10.1111/j.1365-2745.2010.01741.x, 2011.

Wagner, F., Hérault, B., Stahl, C., Bonal, D., and Rossi, V.: Modeling water availability for trees in tropical forests, Agr. Forest Meteorol., 151, 1202-1213, doi:10.1016/j.agrformet.2011.04.012, 2011.

Wagner, F., Rossi, V., Stahl, C., Bonal, D., and Hérault, B.: Water Availability Is the Main Climate Driver of Neotropical Tree Growth, Plos One, 7, e34074, doi:10.1371/journal.pone.0034074, 2012.
Wagner, F., Rossi, V., Baraloto, C., Bonal, D., Stahl, C., and Hérault, B.: Are Commonly Measured Functional Traits Involved in Tropical Tree Responses to Climate?, International J. Ecol., 2014, 110, doi:10.1155/2014/389409, 2014.

Zuidema, P. a., Baker, P. J., Groenendijk, P., Schippers, P., van der Sleen, P., Vlam, M., and Sterck, F.: Tropical forests and global change: filling knowledge gaps., Trends Plant Sci., 18, 413-9, doi:10.1016/j.tplants.2013.05.006, 2013. 